Open Access

\title{
Social class differences in consumption propensity in contemporary China - from survival-oriented consumption to development-oriented consumption
}

\author{
Yi Zhang
}

Correspondence:

zhangyi@cass.org.cn

National Institute of Social

Development, Chinese Academy of

Social Sciences, Beijing, China

\begin{abstract}
This article employs data from the 2013 China Social Survey to analyse class differences in propensities to consume in contemporary China. Results suggest that the average propensity to consume (i.e. APC) among peasants, the working class, and the old middle class is relatively high; but owing to their limited income, the marginal propensity to consume (i.e. MPC) among peasants and the working class is relatively low. By further distinguishing survival-oriented consumption from developmentoriented consumption, the results indicate that survival-oriented MPC is relatively high among peasants, the working class, and the old middle class, whereas the pattern among the new middle class is the opposite, showing a relatively low survival-oriented MPC but a relatively high development-oriented MPC. Results show that in the top-down design of the supply-side structural reform on residents' consumption, survival-oriented consumption should target peasants, the working class and the middle class, whereas development-oriented consumption should target the new middle class and business owners.
\end{abstract}

Keywords: Social class structure, Consumption upgrade, Survival-oriented consumption, Development-oriented consumption

Given the incessant downturns in the global economy, decreases in exports, and shrinking of investment, consumption has become the most urgent driver to "stabilise growth, adjust structure, promote reform, improve livelihoods and control risks". The consumer market in China is now transitioning from waves of emulative spending to a multi-grade, individualized, and diversified consumption style. In order to adapt to new changes in the consumption structure, the Chinese government recently stressed that in the process of expanding total demands, it is of great importance to strengthen the supply-side structural reform, increase high-quality supply, decrease ineffective supply and expand effective supply, promote the adaptability and flexibility of the supply structure, and strengthen the driving force to sustain China's economic growth. Not only do these requests reflect some step-wise upgrades in consumption since China has entered the middle-income stage, they also signal how social stratification in China has caused divisions in the consumer market, which in turn, results in multiple appeals to the supply-side structure of the market.

(c) The Author(s). 2017 Open Access This article is distributed under the terms of the Creative Commons Attribution 4.0 International License (http://creativecommons.org/licenses/by/4.0/), which permits unrestricted use, distribution, and reproduction in any medium, provided you give appropriate credit to the original author(s) and the source, provide a link to the Creative Commons license, and indicate if changes were made. 
As a result, top-down design, which was invented to stimulate internal demands and improve the supply-side market structure, should consider not only consumption preferences among different social classes, but also the characteristics of how the livelihoods of all social classes have improved in the current era and developmental stage. While manufacturers and product circulators have used commodity pricing, commodity quality, and product diversification to construct the supply market, consumers have gradually created a hierarchical pattern of consumption based on their own purchase preferences. This is the basic conclusion gained from sociological studies on consumption. Regardless of the consumption demands of "potlatch"1 or of the "leisure class" (Veblen 1964: 75-95) or rational or irrational consumption patterns (Bell 2010: $119,194,280),{ }^{2}$ consumption trends emerge in the process of social stratification. Under such circumstances, being able to differentiate consumption propensities by social classes has both practical and theoretical implications to both demand-side and supply-side reforms.

\section{Theoretical background, data, and variables}

In the 1960s, W. W. Rostow classified stages of economic growth into "traditional society", "pre-conditions for take-off", "take-off", "drive to maturity", and "age of high mass consumption" (Rostow 1962: 10). In 1971, given observed changes in social development, he added as the fifth stage "beyond consumption" in Politics and the Stages of Growth (1971), further explaining the growth tendency of mass consumption. Since the implementation of reform and opening-up, China has experienced 30 years of rapid economic growth, which has not only transformed the country into the world's second largest economy, but also enabled China to enter the middle-income phase. This transition has to a great extent improved China's consumption structure. Wang (2009): 1) argues that overall, China is still a double-track society with both mass production and elite consumption, but Chinese cities are moving towards consumer societies.

Indeed, after entering the stages of industrial society and subsequently post-industrial society, humans have gradually overcome the shortage of material experienced in the stage of agricultural society. With the introduction of technology and machines, mass production increased the options available for consumer goods, and this eventually has driven the shift from a production-directed society to a consumer society (Bauman 2013: 76-9). Simmel (2001): 70-90) maintains that while the upper-class address consumption heterogeneity, people from the middle and lower classes can reduce their distance from the upper class through "fashion imitation". Jean Baudrillard argues that after having become a consumer society, the focus on material consumption changes from value in use to pursuing social status. As a result, consumption has come to carry more symbolic meanings for different social classes against the backdrop of the great social narrative (Baudrilliard 2001: 68-9, 84-5), such that consumers no longer pay attention to value-in-use but rather the symbolic value of consumer goods. Daniel Bell (2010: 140-7) has provided a fairly detailed analysis of this phenomenon.

Some studies have depicted the epochal character of transitions from societies where commodity shortages exist to those of commodity overproduction and from closed societies to open societies under the influence of globalisation. But the consequences of a volatile market economy are very complicated. In a period of economic growth, the supply of consumer goods will follow Say's Law to automatically generate production 
demands. In a period of economic decline, weak consumption will worsen the economic surplus, forcing the government to cut excessive industrial capacity and destocking. As a result, in recognition of characteristic consumption patterns that are in agreement with social class, we must continue to explore how to enable an optimal match between the needs of each social class (especially that of the lower social class) and policy arrangement, so as to stimulate and satisfy peoples' desire for consumption as well as to adjust the supply-side structure to accommodate the ever-changing demand-side structure. After all, satisfaction derived from consumption, or a sense of gain through comparative reduction of consumption disparity, can eventually promote people's happiness.

German statistician Ernst Engel, a pioneer in developing indices to describe and define consumption disparities across social class, discovered that the percentage of income allocated for food purchases decreases as income rises. Based on Engel's coefficient, the United Nations' Food and Agriculture Organisation (FAO) has classified consumers into "poor, keep the wolf from the door, well-off, rich, and super rich" social classes. ${ }^{3}$ Since the implementation of reform and opening-up, China's Engel's coefficient has declined consistently, from 57.5\% (urban) and 67.7\% (rural) in 1978 to $39.2 \%$ (urban) and $49.1 \%$ (rural) in 2000, later dropping to $35.7 \%$ (urban) and $41.1 \%$ (rural) in 2011; in 2013, Chinese Engel's coefficient declined to 35.0\% (urban) and 37.7\% (rural) (according to The National Bureau of Statistics of the People's Republic of China 2014). Within the background of the Asian financial crisis, Li Peilin and Zhang Yi have discussed the policy implications of boosting domestic demand in China in terms of social stratification, which is indexed Engel's coefficient (Li and Zhang 2001).

However, Engel's coefficient has limitations. Firstly, as income increases, Engel's coefficient will decline in the long run, but fluctuate frequently in the short run, which means it could either rise or decline. Secondly, under normal circumstances, Engel's coefficient for a certain society should be stable; however, under special conditions, such as when tremendous changes occur in the supply structure, consumers' consumption structure shifts accordingly, which in turn, induces a sharp increase or decrease in the proportion of income allocated for other consumer goods. This leads Engel's coefficient to fluctuate widely and to become invalid in measuring disparities of standard of living. For instance, an increase in consumers' rents and purchasing of high-end and durable commodities and high education expenses can reduce the proportion of families' income spent on food. In this case, a decline in Engel's coefficient in fact indicates a pent-up demand and a decreased rather than increased standard of living. ${ }^{4}$ In fact, purchasing expensive "durable consumer goods" by economizing on food and clothing is a kind of consumption preference for some people. Also, under normal circumstances, a mortgage is expected to be paid off in decades; however, in light of economic decline over cyclical fluctuations, people will often reduce the proportion of income spent on food to pay the fixed amount of the mortgage loan. In that case, a decrease of Engel's Coefficient no longer indicates an improvement in living conditions. In fact, a hike in food prices, a decrease in non-food prices, or increasing income disparity together with the comparatively faster growth in income among the upper class (in contrast to the lower class), will affect Engel's coefficient. In other words, an increase in income may not lead to an absolute decrease in Engel's coefficient. 
Moreover, based on the basic principle of Engel's coefficient, we have discovered that a trade-off exists between food consumption (plus necessities for life) and service consumption (plus none of the necessities for life). Hence, dividing consumption into survival-oriented and development-oriented groups can also be used to better examine differences in consumption patterns among social classes. To study income constitution and consumption structure, many researchers have either combined or split income origins and consumption channels using their own approach, in order to achieve nuanced studies ( $\mathrm{Li}$ and Luo 2012). ${ }^{5}$

Theoretically, people are desired to always improve their consumption standards, but due to income limitations, individual consumption priorities vary. Therefore, there emerges a hierarchical structure in consumption patterns in terms of people's needoriented consumption. Friedrich Engels, writing in the preface for Wage Labour and Capital (1891), classified consumption types into "means of life, of the enjoyment of life, and of the development and activity of all bodily and mental faculties" (see Marx 1961). Abraham Maslow's Hierarchy of Needs categorized personal needs into physiological needs, safety needs, the need for love and belonging, esteem, and selfactualization. Maslow argued that people would meet their needs sequentially, that is to satisfy physiological needs first and to satisfy self-actualization last. As for the lower class, to the need for survival is fundamental: humans must survive first, and only then seek development. Adopting a quantitative methodology to distinguish householdbased consumption data from survival-oriented consumption (basic consumption required to maintain household labour for production and reproduction) and development-oriented consumption (pursuit of improved living standards and future development opportunities) ${ }^{6}$ has significant implications for policymakers as they implement top-down design: to not only initiate targeted methods to boost the consumer market, but also to provide recommendations for the supply-side reform.

Unlike economists, who abstract column item analysis of consumption expenditures in terms of money, sociologists mainly focus on individual preferences for consumer goods, given that consumer goods have certain symbolic meanings, consumers' arrangement for consumer sites, as well as the cultural meanings of consumption, across social classes. ${ }^{7}$ For example, relevant surveys usually ask about where people prefer to eat and buy clothing and whether there are computers, TVs, refrigerators, washing machines, or cars in their families, etc. The basic hypothesis for this kind of investigation is that those who eat at fancy restaurants and shop for famous brands belong to the upper social class and, similarly, those who have computers, refrigerators, washing machines, TVs, and cars have achieved a high standard of consumption and should be classified into the upper social class as well. These indexes undoubtedly are meaningful for social classification against the backdrop of a seller's market, or in the early stage of a transition from a seller's market to buyer's market. However, given that symbolic value rather than instrumental value varies greatly across consumer goods in a buyer's market, it is no longer accurate to use the type of consumer good to measure social class. For instance, as for cars, TVs, refrigerators, and computers, product quality differs across brands. If we measure social class by a rough categorization of consumer goods, the subtle differences within such category may not be noticed. On the contrary, if we tirelessly ask for consumption details, such as brand, price, setup, fuel consumption, and place of purchase, it is unlikely of researchers to find consumers responsive to 
the survey (Bourdieu 2015: 300-350). ${ }^{8}$ Despite these facts, given the widespread availability of "counterfeit" goods in China, it is difficult to distinguish fake ones from authentic ones. As a result, studying brand consumption or antique consumption is meaningless.

Under such circumstances, if we ignore the tastes of different classes but assume that products of famous brands are priced competitively and assume that transaction price can reflect the difference in ability to pay across social classes, we can use a family's purchasing power, the current payment for a certain type of goods by a family, or the amount of money paid for a particular service as the basis for discussing markettargeted policies, which are aimed at stimulating consumption. By setting up quantitative models, Gary Becker has vividly portrayed household or individual consumption behaviour as the process of "production and reproduction", that is to say, one can achieve a sense of belonging to a certain social class by purchasing a particular type of goods so as to maximize income utility (Becker 1987: 9-10).

The present research employs CSS 2013 data, which is collected by the Institute of Sociology in the Chinese Academy of Social Sciences. Following the method of random sampling using a nationwide scale, the dataset consists of 10,206 cases, with $50.77 \%$ male and $49.23 \%$ female. As for the geographic distribution of this sample, the northeast, north, east, central, southwest, and northwest regions occupy $8.04,12.08,28.35,29.47,14.75$, and $7.32 \%$ respectively. The questionnaire asks for details on individuals' (households') status in terms of social class, income level, ability to consume, and captures information on household expenditures on food, clothes, utility, rent, maintenance, wedding, education, travel, hygiene, entertainment, home appliances, housing mortgage, commute and transportation, etc. Based on the above information, researchers can analyse every respondent's consumption structure.

By analysing consumer spending in monetary form, the current research investigates actual purchasing power and consumption capability differences by social class. Specifically, this article demonstrates the relationship between consumption and total income by analysing the average propensity to consume (i.e. APC), as well as the relationship between consumption and disposable income by analysing the marginal propensity to consume (i.e. MPC), so as to provide suggestions for policy makers using the class analysis approach. Following are detailed descriptions for the main variables.

Firstly, for the operationalization of concepts, the present study assumes an equal relationship between participants' social class status and that of his/her family's. Some researchers argue against this approach, but they failed to identify alternatives. At the same time, many studies have demonstrated that the father's social class status positively influences the children's social class status; similarly, the husband's social class status is positively associated with the wife's social class status (Zhang 2003). This research identifies participants' social class status through a series of individual data points, such as owning a property (e.g. whether or not they are business owners), the extent to which one's job required skill, and the degree of power domination at the workplace, and further classifies participants into business owners, new middle class, old middle class, working class, and peasants.

Here, the construction of the class system shares similarities with Erik Wright's (2004: 76-92) framework for class analysis. However, there still are some subtle 
differences. For instance, due to differences in land ownership, peasants in China differ in nature from peasants in the West. In Wright's framework, "peasants" are more like farmers, who own land and employ farm workers. In contrast, peasants in China consist of self-employed "farming workers", who share relatively equal land contracts and family-based and self-organised production and reproduction within village groups. Therefore, in discourses on American society, a "farmer" is relatively wealthy, whereas farm workers are generally less wealthy. In view of such facts, we further operationalize the concepts as follows.

Business owners refer to people who own land or businesses and employ others to work for them (Wright 2004: 76). ${ }^{9}$ Wright emphasizes a specific number of employees. But among the CSS sample, the proportion of China's business owners is relatively small, and therefore, I do not distinguish between capitalists (business owners who employ many workers) and petty bourgeoisie (small business owners), but instead integrate them into a general category as business owners.

The middle class is divided into new middle class and old middle class. The reason for dividing the middle class into two sub-classes is not only due to income disparities between them, but also because of differences in family origin, education, division of labor, etc.

Working class refers to blue collar workers employed in various types of industries and enterprises. This social class consists of both semi-skilled workers and manual laborers.

Peasants refer to people working in the fields of agriculture, forestry, animal husbandry and fishery, which also includes farmers, herdsmen, and fishermen involved in the household contract responsibility system. Employed agricultural workers are regarded as working class in the analysis; farmers, in contrast, are categorized as business owners.

Secondly, the average expenditures on food, clothes, utility, housing, medical care, financial support of elderly parents, and spending on wedding and funeral are defined as consumption for a household's basic needs (i.e. survival-oriented consumption). Average expenditures on education, travel, entertainment, household appliances, communication, and transportation are defined as consumption for the household's future (i.e. development-oriented consumption). Regardless of the brands of consumer goods, measuring the improvement in living conditions by the structure of the expenditure is reasonable: spending on education, travel, entertainment, electronics, communication, and transportation are undoubtedly positively related to individuals' development. In general, survival-oriented consumption prioritizes development-oriented consumption. It should be noted that housing expenditures can be categorized into either survivaloriented consumption or development-oriented consumption in terms of its investment function. However, as CSS has not considered this possibility, it is not feasible to further identify and differentiate the nature of housing expenditure in the current analysis. Such issue shall be dealt with in future studies.

This study divides propensity to consume into APC and MPC. The former refers to the proportion of income allocated towards goods and services, namely consumption, rather than on savings; and the latter refers to the percentage of disposable income spent on consumption. ${ }^{10}$ In the main content, I firstly analyse people's propensity to consume by social class based on the absolute income hypothesis and then proceed to 
analyse the survival-oriented MPC and development-oriented MPC of each social class after controlling for the effect of household-related variables.

\section{Distribution of APC and MPC across different social classes}

Consumption is influenced by an income structure. People's income is redistributed within their families; high-income individuals, who are motivated by altruism, would like to give a portion or all of their income to low-income or zero-income members in their families (Becker 1987: 195-203). Consumers can choose to purchase certain goods based on their preferences, but must do so within the allowance of household consumption expenditure per capita. ${ }^{11}$ Thus, concerning the above binding force, household consumption expenditure per capita is a meaningful indicator for studies of consumption.

This article categorizes social classes into business owners, new middle class, old middle class, working class, and peasants. Table 1 shows the distribution of each social class among the total labour force: Business owners represent $4.67 \%$, new middle class represents $12.98 \%$, old middle class represents $13.92 \%$, working class represents $33.50 \%$, and peasant represents $34.83 \%$. It can be seen that, after more than 30 years implementing reform and opening-up, the kernel of China's social structure-the social stratum-has changed dramatically, from having the majority consist of peasants to an even distribution of middle class, working class, and peasants. If we combine the new middle class, old middle class, and business owners all together into a group of abovemiddle class, there is also an even distribution of the above three groups, with abovemiddle class, working class, and peasants representing approximately one third respectively. ${ }^{12}$ Being aware of such shift in the class structure is the basis to understand the current policy-setting in China.

Undoubtedly, the change in social structure in Chinese society has further reinforced the social transition trend, manifesting itself in a transition towards a worker-based and middle-class-dominated society. It is reasonable to argue that both the proportion and growth of the working class in China have reached their zenith. In the future, in the context of the promotion of modernization in agriculture, acceleration of land transfer and the ongoing expansion in college enrolment, the population of peasants and its proportion in the labour force will continue to shrink. In the meantime, under the promotion of post-industrialization in megacities and other provincial cities, the growth of the working class will eventually run out of steam after the proportion of working class reaches a certain level. Like other East Asian countries, the population size of the old

Table 1 Distribution of social class and consumption patterns (initial model)

\begin{tabular}{llll}
\hline & $\begin{array}{l}\text { Proportion of each social class } \\
\text { among the total labour force (\%) }\end{array}$ & $\begin{array}{l}\text { Household consumption expenditure } \\
\text { per capita for each social class (\%) }\end{array}$ & $\begin{array}{l}\text { MPC of each } \\
\text { social class }\end{array}$ \\
\hline Business owners & 4.67 & 44.47 & $0.177^{* * *}$ \\
New middle class & 12.98 & 76.23 & $0.471^{* * *}$ \\
Old middle class & 13.92 & 83.24 & $0.513^{* * *}$ \\
Working class & 33.60 & 83.94 & $0.395^{* * *}$ \\
Peasants class & 34.83 & 101.53 & $0.315^{* * *}$ \\
\hline
\end{tabular}

Because household social class status is indexed by the social class status of the householder, the distribution of social classes is calculated beyond the consideration over size of the household ${ }^{* * *} p<0.001$ 
middle class in China will be influenced by the Confucian culture and finally will remain constant. In contrast, the new middle class in China will keep expanding, and its proportion in the labour force will continue to increase. Like other countries with a market economy, the proportion of business owners in China will not be too big. ${ }^{13}$

With the rapid growth of the new middle class, China's future consumer market will continue to transition incrementally. As the Chinese economy continues to expand, economic growth led by investments will gradually decline. In addition, with increasing involvement of China in the global market, conflicts in international trade will become more frequent, which, in turn, will result in an unexpected relationship between foreign investment and domestic economic growth. Under such circumstances, the impact of domestic consumption will become more important than ever.

The process of social stratification is driven by the widening income disparity. Although in recent years, the Gini coefficient announced by the National Bureau of Statistics has slowly dropped, it was still as high as 0.462 by the end of 2015 (Li 2016), indicating that China has a high level of income disparity. In fact, the uneven distribution of APC also suggests that income disparity exists. In Table 1, it is shown that the APC of business owners is $44.47 \%$, and that of the new middle class is $76.23 \%$, the old middle class $83.24 \%$, the working class $83.94 \%$, and the peasants $101.53 \%$. The reason why that the APC of the peasants exceeds $100 \%$ is that for extremely poor families, they still have to consume to meet their basic needs for a living even if they have no income. Such results exactly demonstrate the incremental decrease in APC across social classes as described by Keynes-as average income increases, APC decreases. People who receive relatively high incomes, such as business owners, will allocate a small portion of their income to consumption, and the rest of their income is either saved or used for investment. In contrast, people with relatively low incomes must spend most or all of their income on consumption, in order to keep up with society's development.

Households' MPC does not decrease for those with lower social class status, but with middle class to be the higher, and business owners together with peasants to be the lower (as seen in Graph 1). Based on the 2013 CSS data, it is shown that, as income increases, some social classes (the new middle class, old middle class, and working class) allocate a comparatively larger proportion of their disposable income to consumption than others do (i.e. business owners and peasants).

The above results have important policy implications, which are briefly analysed as below. Firstly, economic growth can be stimulated by increasing domestic demands to boost the income of the lower class. While the upper social class, in contrast to the lower social class, has a larger allowance for household consumption expenditure per capita, they present a relatively small proportion of the population and have a comparatively lower APC. Their consumption will stop rising after reaching a certain level and, thus, no longer boost demand so as to effectively stimulate economic growth. In the case of high income disparity within a society, there should be a comparatively larger percentage of business owners, as the lower social class can only consume less due to lack of resources, whereas the upper social class are less motivated to consume since their consumption demands have been fully met. When the domestic market no longer satisfies the upper social class, shopping abroad (including online shopping) becomes their preferred option, which is expected to fulfil their unsatisfied demand for purchases, eventually leading to a "spillover effect", while external demands transferred 
by internal demand will positively stimulate the global market, but will negatively influence the domestic market. In order to avoid such a situation, it is vital to improve the competitiveness of Chinese brands and provide the upper social class with alternative options for consumer goods on the supply side. Without decent growth in value and competiveness of product and services brands, it will be impossible to promote a fast shift among the upper social class from shopping abroad, which will conversely result in a negative impact on the effects of policies aimed at boosting domestic demands (Fig. 1).

APC results APC show relatively high enthusiasm for consumption among the new middle class, old middle class, working class, and peasants. Moreover, this suggests a greater consumption potential among peasants, working class, and old middle classes, who together constitute more than $80 \%$ of the entire Chinese labour force (see Table 1). Any increase in their income would not only stimulate domestic demand, but also improve the quality of life in Chinese society. In the long run, though it is a long process, increasing the income of the lower social class can better fuel growth in domestic demands. Once formed into an income structure or solidified pattern of wealth distribution within a society, it will be very difficult to make any adjustment. In addition, when the management and technology of Chinese enterprises are less than adequate, merely increasing labour cost would even negatively affect global competitiveness. The so-called middle-income trap in essence refers to a situation in which a society enters the middle-income stage at the same time that the labour cost growth rate surpasses that of labour productivity determined by technological innovation, and this eventually terminates any increase in the competitiveness of enterprises. Therefore, regardless of whether we are referring to peasants, working class, or old middle class, an increase in their income should be synchronized with an increase in the nation's labour productivity. Any change in consumption structure is affected by the shift in income structure; any shift of income structure relies on the transformation in the structure of industrial technologies, which is fundamentally determined by the structure of the economic market and rate of technological innovation.

Secondly, the inverted $\mathrm{U}$ shape of the $\mathrm{MPC}^{14}$ proves that an increase in income will not lead to an increase in the proportion of consumer spending on disposable income among business owners, and the expected boosting effect of the income

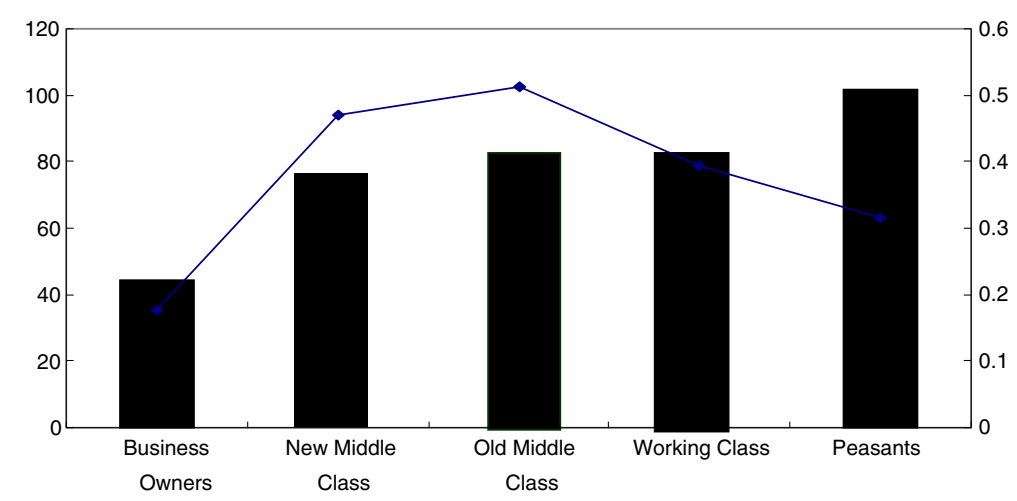

Fig. 1 Average consumption tendency and marginal consumption tendency of each class (curve represents marginal consumption tendency) 
increase on spending is limited to the type of consumption among peasants. There is a comparatively higher level of MPC among the new middle class, old middle class, and working class: the old middle class shows the highest MPC, as they have abundant reserves to meet their daily life requirements, which sustains a decent life for them. In addition, some people in the old middle class are landless peasants who just "upgraded" to become citizens in the process of urbanization. As they relocate to cities, they are given storefronts for self-employment as compensation for their loss of land. Such life transition motivates them to buy consumer goods and property in the short run.

One interesting finding is a high level of APC accompanied by a low level of MPC among peasants. One possible reason is that many peasants are still self-sufficient for their basic living needs through growing vegetables, grains, and some kinds of fruits and, therefore, have not participated in the exchange of commercial goods. Also, they barely have any demand for buying services. In addition, they have limited access to medical care and are less likely to receive social security benefits and, thus, have to save money for their own health care and long-term retirement needs. To date, villagers' pension payments have been far smaller than those of urban workers; while the new rural cooperation medical system (i.e. NCMS) has improved medical care for villagers, there are still many problems when it comes to reimbursement and medical charges. Even though hospitals participate in NCMS, only a small portion of medical expenditures (payment for medicine, treatment, or examinations) is covered by a medical insurance, which, to a great extent, peasants' capability to consume. In the mid-western part of China, there are some remote villages where the prevailing norm is to economise on food and clothing. Filial piety has long been a tenet of traditional Chinese culture; thus, children are obligated to take care of their elderly parents. However, many young villages have relocated to urban areas, and their relatively high consumption of real estate and commercial goods leaves them little capability to provide financial support to their parents. Such fact results in a series of social issues, which simultaneously emerge in rural areas, such as an aging population, an empty nest among elderly people, population loss, as well as increasing scarcity of public services and public goods. On the one hand, the elderly need to save money for the latter when they are unable to care for themselves; on the other hand, the market-oriented redistribution of public goods and services from rural to urban areas has limited peasants' access to consumer goods and further reduced consumption demand.

As for the new middle class, there is a high level of human capital and cultural capital, as well as fairly stable income and social insurance. Thus, the new middle class have greater ability to consume than others and are of the highest MPCs among the whole population. They no longer pursue consumer goods for the instrumental value and instead go after the symbolic value of commodities. Such consumption preference has been further stimulated by globalization. As the features of post-industrialized society become increasingly salient, the consumer preference of the new middle class for consumption of goods with symbolic value will be further strengthened. As their pursuit of symbolic value exceeds that of instrumental value, social stratification will become more exaggerated. By then, domestic and even global manufacturers will compete for consumers by targeting different social classes. 
Today, the population of the new middle class continues to expand, the old middle class remains unchanged, the working class has grown to a decent size, the peasant class is shrinking, and the features of the "middle-to-high-income" stage has become more salient. Against this backdrop, domestic manufacturers in China must focus on how to cater to the needs of different social class markets, so as to develop its own consumer base in competing with global manufacturers and global brands. If Chinese manufacturers cannot effectively target the increasingly divided Chinese market, they will fail to improve their own competitiveness.

\section{Distribution of survival-oriented and development-oriented MPC across different social classes}

When the proportion of survival consumption is relatively high, people remain in a state of survival-oriented consumption; but when the proportion of developmentoriented consumption is relatively high, people remain in a state of developmentoriented consumption. Obviously, the higher the development-oriented MPC of certain social classes, the greater the extent to which their standard of living is improved.

Table 2 shows that in the extended model of survival-oriented consumption, the MPC of the peasants, working class, and old middle class are relatively high, reaching $0.259,0.241$, and 0.302 , respectively, whereas the MPC of new middle class is only 0.168 . The MPC of business owners is as low as 0.002 at a non-significant level. It can be said that in current China, peasants and working classes still consume to survive, spending more money on clothes, food, accommodation, utility, medical care, pension, weddings, and funerals, etc., due to their limited incomes.

For villagers, expenditures on wedding and funerals are inevitable. In an acquaintance society, it is important to main social networks as well as friendship and kinship networks through regular engagement in ceremonies. Peasants can only cut spending on items other than those that aim to maintain social relationships (renqing). The reason is that, in traditional Chinese society, each person's relationship with others is based on a differential mode of association that centers on the self and then extends outwards, first to parents, spouse and siblings, and then to the extended family, to the lineage group, and finally to unrelated members of the society. In order to maintain a safe social network, from which they can get social support to overcome difficulties, they need to pay a justifiable amount of renqing fee ${ }^{15}$ to maintain a reciprocal relationship. This has to some extent encouraged expenditures on weddings and funerals. Moreover, as the price of land rises and the development of new villages accelerates, peasants' housing expenditures have increased dramatically. The transition of housing made with wood and earth and then to masonry and then to cement buildings, accompanied by the transition from bungalow to multi-story apartment buildings, shows the advancement of the entire society. However, as for the poorest families, if their housing conditions do not keep up with housing renovations in the community, they will experience pressure from comparisons with their neighbours-an effect similar to "potlatch". In the meantime, in recent years, the government-led project of "rebuilding country roads" and "repairing damaged houses" has also stimulated villagers to invest in housing. For peasants, spending on medical care and care for the elderly is also a major expenditure. Although NCMS has to a large extent strengthened access to medical resources, the most reliable hospitals are mainly located in towns and major city centres. In such case, 
Table 2 Distribution of MPC by class in terms of survival/development-oriented consumption (extended model)

\begin{tabular}{|c|c|c|c|c|c|}
\hline \multicolumn{6}{|l|}{ Survival-oriented consumption } \\
\hline & Peasants & $\begin{array}{l}\text { Working } \\
\text { class }\end{array}$ & $\begin{array}{l}\text { Old middle } \\
\text { class }\end{array}$ & $\begin{array}{l}\text { New middle } \\
\text { class }\end{array}$ & $\begin{array}{l}\text { Business } \\
\text { owners }\end{array}$ \\
\hline Constant & $3144.867^{* * *}$ & $3092.476^{* * *}$ & $4892.054^{* * *}$ & $3233.185^{* * *}$ & $7155.003^{*}$ \\
\hline Household income per capita & $0.249^{* * *}$ & $0.241^{* * *}$ & $0.302^{* * *}$ & $0.168^{* * *}$ & 0.002 \\
\hline Household's residence $($ town $=1$ ) & 215.516 & $1280.117^{* * *}$ & -459.356 & 1638.880 & 2221.005 \\
\hline $\begin{array}{l}\text { Household's savings and credits/deposits etc. } \\
\text { per capita }\end{array}$ & -0.016 & $0.041^{* * *}$ & -0.030 & $0.020^{* * *}$ & $0.078^{* * *}$ \\
\hline Household's years of education per capita & 246.553 & $995.813^{* * *}$ & 64.349 & $357.643^{* *}$ & 230.585 \\
\hline $\begin{array}{l}\text { Present value of household's durable } \\
\text { consumer goods per capita }\end{array}$ & $0.039^{* *}$ & $0.056^{* * *}$ & 0.017 & 0.000 & $0.061^{* * *}$ \\
\hline $\begin{array}{l}\text { Present value of household's production } \\
\text { and operation per capita }\end{array}$ & 0.001 & $0.018^{* * *}$ & 0.000 & -0.005 & -0.002 \\
\hline N & 1830 & 1562 & 688 & 584 & 195 \\
\hline Adj $R^{2}$ & 0.130 & 0.292 & 0.248 & 0.273 & 0.552 \\
\hline \multicolumn{6}{|l|}{ Development-oriented consumption } \\
\hline & Peasants & $\begin{array}{l}\text { Working } \\
\text { class }\end{array}$ & $\begin{array}{l}\text { Old middle } \\
\text { class }\end{array}$ & $\begin{array}{l}\text { New middle } \\
\text { class }\end{array}$ & $\begin{array}{l}\text { Business } \\
\text { owners }\end{array}$ \\
\hline Constant & 370.617 & -955.624 & -765.375 & -4255.860 & - \\
\hline Household income per capita & $0.096^{* * *}$ & $0.146^{* * *}$ & $0.204^{* * *}$ & $0.257^{* * *}$ & 0.002 \\
\hline Household's residence(town = 1) & 97.827 & 430.309 & -609.307 & 4847.203 & 2891.371 \\
\hline $\begin{array}{l}\text { Household's savings and credits/deposits } \\
\text { etc. per capita }\end{array}$ & -0.033 & -0.012 & 0.017 & -0.029 & $0.073^{* * *}$ \\
\hline Household's years of education per capita & $364.917^{*}$ & $873.236^{* *}$ & 822.760 & 1564.047 & 4921.152 \\
\hline $\begin{array}{l}\text { Present value of household's durable } \\
\text { consumer goods per capita }\end{array}$ & $0.168^{* * *}$ & $0.236^{* * *}$ & $0.144^{* * *}$ & $0.054^{* *}$ & $0.278^{* * *}$ \\
\hline $\begin{array}{l}\text { Present value of household's production } \\
\text { and operation per capita }\end{array}$ & $0.043^{* * *}$ & $0.047^{* * *}$ & 0.000 & 0.005 & -0.003 \\
\hline N & 1872 & 1612 & 710 & 598 & 200 \\
\hline $\operatorname{Adj} R^{2}$ & 0.092 & 0.236 & 0.225 & 0.098 & 0.231 \\
\hline
\end{tabular}

A series of variables are controlled in the extended model of absolute income hypothesis including household's residence, household's savings and credits/deposit etc. per capita, household's years of education per capita, present value of household's durable consumer goods per capita, present value of household's production and operation per capita

${ }^{*} p<0.05 ;{ }^{* *} p<0.01 ;{ }^{* * *} p<0.001$

patients are usually accompanied by several family members, who take turns caring for him/her. This situation results in costs that exceed simply paying for medication, including the cost of a caregivers' accommodation and daily expenses in urban areas, which further increase their debts. Such fact to a large extent has restricted development-oriented MPC among peasants, which is only 0.096, as shown in Table 2.

The working class in China is currently improving its standard of living. This majority of this social class consists of migrant workers and also includes a small proportion of state-owned enterprise workers. ${ }^{16}$ The latter's income is relatively stable and is protected by the "wage adjustment" policy, which is based on change in the local price level. Pensions for workers in urban areas have increased by $10 \%$ each year for the last 11 years, ${ }^{17}$ which seems to guarantee the living standard for their future life. As a result, consumer confidence has risen gradually and further improves their standards of 
living. But there is only a limited number of workers at state-owned enterprises. For migrant workers, although their income has increased due to the volatility of the economic market, the absolute increase in income has not improved their living standard due to price hikes in rent and food. Especially for male migrant workers, owning a house in their local area is an essential prerequisite before getting married. Increase in housing prices in urban areas depletes the savings of the buyers' families and restricts their ability to spend on other goods. ${ }^{18}$ Migrant workers or their families have to work hard for years in order to save up for a down payment on a home and then continue to pay the mortgage, which restricts their current spending in the long run. Since they need to satisfy a decent level of survival-oriented demands, they are barely able to consume for development. It must be stressed that because migrant workers do not have hukou (registered residence permit) in their residence, they are less likely to integrate themselves into society, which further hinders their ability to consume. Since they float across different cities, and are uncertain of their permanent location, they must focus on survival-oriented consumption rather than development-oriented consumption. For migrant workers, separation from their family members also inhibits their households' ability to consume. Results show that working class MPC is only 0.146, higher than that among peasants, but still lower than that among either the old middle class or the new middle class.

The old middle class make a living by self-employment. With the majority of them working as self-employed small business owners, a new social group emerged since the Reform and Opening-up. The rest are migrant workers who accumulated some wealth and started their own businesses in the urban areas of their hometowns or where they used to work. It is very common for such businesses to be run by married couples (the aging population in urban areas makes it possible for these couples to be employed). Some landless peasants who are compensated with storefronts as a form of compensation will become small business owners. Working in the lower-end of service and facing intense competition within their social class, such individuals have relatively limited income. But family members from this social class stand in solidarity with each other, and therefore, they tend to show a high level of survival-oriented MPC and, hence, are motivated consume for development as well. Their development-oriented MPC is 0.204, being the second highest among the entire population.

The new middle class has experienced rapid improvements to their quality of life. People in this social class have normally been educated in college or above; their income is generally higher than those of the peasants, working class, and old middle class; therefore, they are white collar in terms of their occupations. Newcomers to this social class are often under pressure to purchase real estate in the cities where they work; however, after acquiring a real estate, they gradually break through the restrictions of survival-oriented consumption. Overall, such social class reveals itself to have a relatively low level of MPC in terms of survival-oriented consumption but a high level of MPC in terms of development-oriented consumption. Therefore, they actually manifest the current trend of consumption upgrade and personalized consumption style: they are well aware of the significance of human resources and thus more willing to invest in education and sending their children to study abroad; as they understand the special symbolic meaning of commodities and pursue the market value of brands, they pay a lot of attention to physical and mental health and have become primary 
consumers in cosmetics and health/fitness markets; they frequently update their home appliances as a result of the technological revolution; they are also the primary consumers in the car market and are drivers of China's push to become a country "on wheels", they are fond of self-driving tours and thus stimulate the tourist economy. Moreover, they have created the weekend consumer market, boosting businesses that provide urban hotels and restaurants, as well as entertainment in rural areas. As a result, the development-oriented MPC of the new middle class is higher than any other group at 0.257 .

Surprisingly though, business owners do not typically show either survival-dominated or development-dominated consumption patterns. Even though we controlled for other variables (e.g. fixed assets of household's productivity per capita) in the model, why is development-oriented consumption among business owners so low, a fact demonstrated by the insignificant effect of household income per capita on developmentoriented consumption? Given that these individuals are supposed to be the wealthiest among the population, this seems surprising. The initial assumption was that business owners, who employ others for labour, are at the top of society in terms of income, should be more likely to pursue developmental-oriented consumption and thus show a high level of developmental-oriented MPC. However, the results indicate the opposite. Two possible explanations are as follows: on the one hand, a portion of this their development-oriented consumption is included in the purchase cost of their private businesses or companies, that is, it is common for business owners to buy their household's electronic appliances, cars, and real estate (which aims to improve their living standard) under the name of their business or company. ${ }^{19}$ Similarly, expenditures on overseas travel, education, entertainment, communication, and transportation of the business owners and their family members could also be included in regular businessoperating expenses. For some small family businesses, it is common for family expenses to be mixed in with operating expenses. Thus, the insignificance of this MPC does not necessarily indicate a conservative consumption style among this social class.

It can be seen that changes to the social structure in China-particularly change in social class structure-has caused a significant differentiation in the consumer market. Peasants and the working class have relatively survival-oriented MPC; the old middle class has strong flexibility in terms of survival-oriented consumption and also a strong desire for development-oriented consumption; the new middle class has shifted its consumption focus from survival-oriented to developmentoriented. In contrast, as an emerging social class, the business owners' class has already transitioned to development-oriented consumption that is characterized by pursuit of pleasure, primarily focused on certain service-based consumer goods (note that hedonic consumption is categorized as development-oriented consumption). Although the mass media often reports cases of the business class showing off their wealth, it is not feasible to run such as analysis due to the absence of relevant information in CSS from 2013.

Understanding the survival/development-oriented MPC of each social class is of great significance; on the one hand, it helps the government to set economic policies that aim to stimulate consumption with specific targets; on the other hand, it suggests implications for the market to make initials in the supply-side structural reform, which aims to address class-based demands to improve living standards. 
Firstly, the peasants and the working class are powerful sources of survival-oriented consumption, whereas the old middle class is the main force behind both survivaloriented and development-oriented consumption. As the economy grows and society develops, these three classes have experienced increases in consumption and their living conditions to some extent. Life expectancy in China has risen to 75 years, ${ }^{20}$ a result of improvements in the living standard, which was promoted by the reform and opening-up. But this has also raised society's poverty line and general living standard to higher levels. Being able to eat properly, wear warm clothes, watch TV, and install gas stoves and electromagnetic benefits derived from economic growth and social advancement. Given the ongoing land transfer and the increasing construction of multi-story buildings in villages, survival-oriented consumption among peasants will continue to increase. The two aid programmes known as "taking home appliances to the countryside" ${ }^{21}$ and "taking cars to the countryside", ${ }^{22}$ both launched in 2009, also helped to further survival consumption the among peasant class. As for the working class, after completing a consumption reform whose primary feature was "updating home appliances by trading in old appliances", there will be a new round of consumption stimulation in the field of home decoration. Rising incomes will breed new types of demand and further heighten concerns over the quality and safety of consumer products, pushing for reform to the supply-side structure from the demand side.

Of course, this change in China's social structure will cause a major transition in the structure of food consumption. There has already been a shift from being based solely on grain to being based on a combination of grain, meat, poultry, and eggs, from consuming foods produced with fertilisers and pesticides to the ones that focus on health, are pro-environment, and ensure safety, as well as development from low-end to highend medical services. Such changes have already occurred among the new middle class and business owners' class, and these changes are ongoing among peasants and the working class as well. Overall, there is still a significantly higher level of consumption in regards to expenditures on grain, meat, poultry, eggs etc. among the peasant class and working class and old middle class, in contrast to that among the new middle class and business owners. Within the background of an aging society, health care for the elderly should be viewed as one important aspect of survival-oriented consumption. As for demands in this area, there can be rigid demand without any market stimulation; it is only a matter of whether the supply side accurately targets these differentiated needs across the social classes. One important characteristic of TV, radio, and other forms of media commercials is to sell health care products to the elderly, although these products are rarely effective or safe, leaving large profit margins for speculative druggists. Such facts can be easily revealed by the huge variety of health/nutritional products in the homes of the elderly living in urban areas. ${ }^{23}$ Hence, improving the structure of survival-oriented consumption can provide guidelines for the development of consumption in general, which is consistent with the aim of the supply-side reform as well. However, the cheap, fake, and inferior products flooding the low-end market have severely violated the consumer rights of peasants, working class, and old middle class. In terms of survival-oriented consumption, a significant mismatch still exists between the supply side and demand side in China's market structure.

Secondly, the new middle class and business owners are the main force behind development-oriented consumption. Whether in big, medium, or small cities, they have 
driven the upgrades of consumer goods in either metropolitan areas or medium/small cities. However, owing to the rapid growth in development-oriented consumption, the qualities of consumer products and services provided by the domestic market can no longer satisfy these three classes; as a result, a structural shortage has emerged, which has further boosted the growth in sales from luxurious cars to very individualised cameras, foreign high-end products, smartphones, handbags, and cosmetic products-foreign brands have taken up a large portion of China's consumer market. A major problem faced by most Chinese enterprises is the mismatch between the huge consumption drive (brought about by the rise in the Chinese middle class) along with the ever-expanding consumption desire (among business owners) as well as a shortage in development-directed consumer goods in the domestic market. From a 2015 report on smartphone consumption, it seems that in spite of the obvious economic downturn, Apple's latest release-the iPhone $6 \mathrm{~s}$ and $6 \mathrm{~s}$ Plus-were sold out immediately in the presale period. Since consumption is mainly driven by symbolic value, advertising, and the hegemony of market discourse rather than the instrumental value of products, consumption is further promoted by intensified competition among merchants. In addition, consumption in the field of education, health, fitness, entertainment, tourist markets, etc., which are categorized as development-oriented consumption, remain to be further developed. In terms of the development of consumption, access to goods and quality of service in developed areas both remain poor. It is important to understand how to improve production and work efficiency for the whole society, to shorten people's work hours and increase the "leisure supply" during holidays and weekends in order to develop policies that aim to improve consumption. It is clear that there is a mismatch between demand and supply rather than a simple shortage of supply given that overseas shopping has changed, from buying luxury products to instead purchasing daily necessities and medicine. This causes a spillover effect. In fact, the trend of shopping abroad cannot be turned back until such problem is solved.

\section{Conclusion and discussion}

Recently, the pulling effect of consumption on the national economy has been increasingly strengthened. Thus, economic growth is more likely to be driven by consumption rather than by investment (The National Bureau of Statistics of the People's Republic of China 2015). However, results of further analysis reveal that, under the constraining condition that economic development is driven by a certain amount of consumption, in terms of all the elements that increase GDP, it is actually the relative shrinking of investment and export that has caused the proportion of consumption to remain comparatively larger. Since it is difficult to boost external demand, it is vital to further stimulate internal demand. Consumption upgrades are not only the result of social and economic development, but they are also a necessary path through which to improve the living standards of people from all social classes.

Since the reform and opening-up, the dramatic change in China's social structure has to a large extent improved China's consumption standards, which in turn, changed the internal structure of the demand side and invoked the consumption desire for individuals from all social classes to improve their quality of life. But commodities provided by Chinese manufacturers cannot keep up with internal changes to China's 
consumption market structure, changes that inhibit consumer demand such that the potential of China's consumer market cannot be fully realised. The purpose of the supply-side structural reform is to bridge the gap between the supply of products and transitioning demands. Different demands for development-oriented and survivaloriented consumption across all levels of social classes can create a strong force for the market. But when poorly produced products flood the market, especially products of low quality and those that pose security risks, it not only betrays consumer values demanded by the upper social class, but also violates the consumer rights of the lower social class. Therefore, if the supply-side structural reform can bring about revolutionary innovation, the market will positively respond to the change in the demand-side structure.

To sum up the above, based on a step-wise analysis regarding how to improve the consumption structure of all social classes, as well as the results of APC, MPC, and survival/development-oriented consumption among all social classes, it is reasonable to draw these conclusions.

Firstly, for the middle class and lower social class, income growth is vital to permit consumption upgrades and improvements in their living standards. APC results reveal that there is stronger consumption potential among peasants, the working class, and old middle class. They are eager to change their current lives through consumption. But their low income level limits their ability to consume. Under the condition of limited rate of income growth, their consumption demands will be maximized when they expect their future life to be safe and secure. However, the function of insurance, which is supposed to be derived from social security system, has yet to be sufficiently developed. As China's economic environment becomes increasingly complex, it is unlikely to implement proposals that are simply a slogan.

As for peasants, within the background that international food prices are lower than domestic food prices, and the fact that there is a low level of cultivated land per capita in China, the method of improving income by increasing food production is no longer viable. The amount of direct food subsidies, comprehensive agricultural capital subsidies, and fine breed subsidies are very limited. Also, the pension bonus system and the NCMS built through payment transfer are both coming to an end. Due to the influence of inflation, the insurance provided by the "low security and wide coverage" programme is becoming ineffective. Economic downturns affect the growth in central finance, which to some extent, weakens the operational ability of government-led policies that aim to develop the lower social class through payment transfers. The steady income growth among peasants can only be achieved by modernization in agriculture. The aging peasant population is becoming a threat to the sustainability of agriculture and village livelihood. Therefore, peasant income should be increased by improving labour productivity efficiency, creating beneficial land transfers, and greatly reducing the population size of peasants so as to improve cultivated land per capita. Only when peasants' income becomes higher than or equal to that of migrant workers will young adult villagers be willing to stay or return home to work as peasants are able to satisfy their consumption demands.

The Chinese working class has experienced a large increase in personal income for the past decade. Migrant workers have employed strategies such as "voting by foot" and "resistance among the weak" to change labour relations at the end of the twentieth 
century and improve their own working environment. However, due to slow progress in technology, low level of craftsmanship, and industrial automation, the competitiveness of Chinese products in the global market has been significantly limited. It is less possible to increase income by "triangle" negotiation, due to profit deductions by enterprises. Thus, boosting the speed of scientific innovation is now a prerequisite to improving income standards for the working class. High housing prices in urban areas has intensified mortgage and rental pressure for the working class, creating a trend of "working for banks," a problem that the whole society complains about. Inflation places more constraints on lower social class consumption than on upper social class. Under such circumstances, if the cost of survival, such as consumption of food and clothes remains uncontrolled, the consumption force among the working class cannot be released. As a result, the living standards of the working class cannot be improved, either. As the demographic dividend gradually disappears, improving labour efficiency will be the primary means by which to improve the income of the working class as well as its ability to consume.

The old middle class still has a desire for both survival-oriented and development-oriented consumption; however, for those working in the service industry, their income growth has been gradually shrinking. In the meantime, for those who run businesses in physical stores, there is also a lack of customers, mostly due to the prosperity of online shopping. Also, competition in the lowerend market further decreases their profits. On the other hand, supportive policies designed to help local start-up businesses have yet to be implemented. Although people in the old middle class want to expand their businesses, severe market competition and erratic economic fluctuations have compressed their space for further development. They can no longer win opportunities by "throwing a sprat to catch a herring" as one did in the early stage of the market transition. In this case, to increase the income of the old middle class relies not only on a good grasp on the market, but also on improving the quality of business services.

Secondly, the upper and middle social classes, namely, new middle class and business class, have already transitioned from survival-oriented consumption to development-oriented consumption. Their income is relatively stable; they are the first beneficiaries of technological advancements and growth in labour productivity. Their ability to resist social risks is much stronger than that for the lower social class. These two social classes pay a lot of attention to the internal value of consumer products in terms of food, clothes, and housing. As for developmentoriented consumption, they are more likely to seek brand values of high-end services. In order to satisfy their materialistic demands, they would also pursue spiritual satisfaction, which would make them more fastidious than the lower class when buying cultural products. There exists a shortage in high quality, individualised, symbolically valued, and ethnically unique material goods, as well as a short supply of high-quality cultural products, such as movies, musicals, plays, and TV series, showing not only historical and ethnic richness but also a high level of artistic expression. So far, the Chinese society has manifested a state of severe contradiction; on the one hand, there is mass production of cheap and slipshod products that have been rejected by the new middle class, including TV shows with low ratings and movies with low attendance rates; on the other hand, 
imported Hollywood blockbusters have been box office hits in China. Given such a supply pattern, to boost consumption among the new middle class and business, one must reduce the disparity between the increasingly refined consumer taste of these two classes and the supply of high-quality cultural products made in China. Additionally, we should also develop and innovate spiritual products of philosophy and social sciences that are consistent with the cultural development of our times, so as to guide people's world views during the process of modernisation and postmodernisation. If there is a mismatch between the prosperity of our material culture and the enrichment of our spiritual world, it would be easy for the upper social class to develop a highly materialistic consumer attitude that will weaken the whole society's developmental value.

Thirdly, it is important to distinguish between the production and supply patterns for survival-directed and development-directed consumer goods. The consumer demands of peasants, working class, and old middle class are mainly concentrated on survivaloriented needs; therefore, it is feasible to continue massive and categorized production. After all, people with low incomes tend to prioritize the instrumental value of consumer goods, which would further lead to waves of emulative spending. In contrast, the new middle class and business owners have already transitioned to a more specialised, multivariate, intergenerational, and hierarchical consumption style such that it is crucial for Chinese manufacturers to integrate craftsmanship with information technology, commodity production with the internet, practicing individualization, customization, and specialization in production. This can help manufacturers transition from the stage of mass production to the stage of small-batch customized production and, finally, to the stage of individual-customized production. The wide use of the Internet, social media, and smartphones has enabled consumers to access product information online, developing a solid foundation for online shopping. As for the service industry, innovation must be centred on the needs and demands of consumers, developing various types of health care, education, entertainment, tourist, pension-related, leisure, and environmental products to cater to the tastes of the new middle class and business owners.

In fact, the transition from survival-oriented consumption to developmentoriented consumption and the shift from buying durable consumer products to service products within the domain of developmental-oriented consumption are two inevitable processes. For instance, in the process of turning peasants into migrant workers, the quantity of service consumption in society will increase rapidly; in the process of turning peasants and the working class into middle class, the quantity of service consumption will also rapidly grow. Even the production and services initially performed within the family (including activities such as cleaning and cooking to looking after children and the elderly) will also shift to the outside as the social service industry expands. At the same time, the consumer tastes of different classes and consumers demand to satisfy such tastes will not only provide space for the individualization of commodities, but also create a supply of consumer services that are more convenient and individualized.

Fourthly, polices that are aimed at stimulating consumption, especially those preferential policies, must impartially evaluate the income of each social class so as to ensure that all people can benefit from the reform and opening-up. By 
examining the development of society in different stages of reform and openingup, it is obvious that, in the period of economic downturn, policies made to stimulate consumption usually prioritize the upper social class but rarely pay any attention to the benefits of the lower class. For example, in 2011, in order to strike down speculation in real estate, the government issued a restrictive policy on home purchases to impose a housing tax for buildings resold within 5 years. But from March 2015 onwards, the government changed the policy and only imposed a housing tax for buildings resold within 2 years. Such policy implementation reduced pressure on the financial capital used for speculative real estate; on the one hand, it helped people to make profit from earlier real estate purchases; on the other hand, it lured such people to further transfer their money to urban centers for further speculation. Also, the announced bank policies tended to encourage the wealthy to have multiple properties. For example, enterprises face no restrictions on home purchases; for certain commercial buildings/stores, there are limits neither on loans nor on purchase amounts. These policies have to a large extent increased income disparity and the wealth gap in China. The working class buys a home as survival-oriented consumption but may have to pay off life-long mortgage loans, whereas the government's economic stimulation policies have made it convenient for the new rich class to speculate in real estate and gain huge profits from price differences in the name of improving their living standards. This has in turn exacerbated economic inequalities across social classes. ${ }^{24}$ The linkage between income disparity and consumption disparity has a profound influence on Chinese society. In this case, what is the purpose of development? And what are the results of development? Correctly answering these two questions can help adjust the distribution of benefits, which derive from the policies that aim to stimulate the market. Building a dynamic policy, one that aims to produce equilibrium among all social classes, must be undertaken carefully. This is the also an inevitable path to modernizing China's systems and governance capacity. In order to reduce consumption disparities, it is important to increase the government's investment in welfare for the lower social classes. Legislating reactive policies to merely treat the symptoms of economic inequality or policies that are designed without any assessment of social justice, while they may appear to stimulate the economy, can actually result in hidden risks and increase the future cost of social governance.

By employing the approach of social class structure and distinguishing survival-oriented consumption from development-oriented consumption, the present study investigated some current issues regarding consumption in China. Theoretically, this article helps sociologists to examine issues related to social stratification and consumption from the perspective of the structure of household consumption per capita. In practice, it helps to better execute social and economic policies by providing a better understanding of the internal demands for consumption upgrades among different classes. In order to stimulate consumption, we should design economic policies based on the class status of various households and their ability to increase their consumption. Against the backdrop of the economic downturn, this is the only way to stimulate the market given existing limits on social and economic resources and to have a positive influence on the demand side by reforming the supply side. 


\section{Endnotes}

1"Potlatch" is a concept created by Franz Boas, which was later further explained by his student, Ruth Benedict, as "Kuakiutl Potlatch"; it indicates conspicuous consumption patterns in order to showcase one's wealth and further distinguish oneself from others. Thorstein B. Veblen also attributed the consumption of the leisure class to conspicuous consumption.

${ }^{2}$ Daniel Bell differentiated consumer disparities as being under the influence of rationalism and irrationalism, pointing out that in post-industrial societies, "needs" have been replaced by "wants".

${ }^{3}$ Based on FAO regulations, Engel's coefficient above 0.60 indicates the poorest class, between $0.50-0.59$ is keeping the wolf from the door, between $0.40-0.50$ is welloff, between $0.30-0.40$ is rich, and below 0.30 is super rich. See Li and Yi 2001.

${ }^{4}$ Apart from housing, many elements may impact Engel's coefficient, e.g. education expenditures, health care expenditures, or increases in nursery elderly care due to immobility, all of which can reduce the percentage of food expenditures.

${ }^{5} \mathrm{Li}$ and Luo (2012) studies show that disparities in education, medical care, and health expenditures, etc., may not only influence people's current income gap, but can also have great impact on children's developmental opportunities.

${ }^{6}$ Consumption for personal enjoyment can be seen as part of a developmental consumption.

${ }^{7}$ See related studies: Dai and Lu 2001; Zhou Xiaohong 2005; Li 2011; Wang 2007; Zhu 2012.

${ }^{8}$ When analysing the consumption tendencies of different classes, Pierre Bourdieu has simultaneously discussed the traditional characteristics and epochal characters of cultural capital, consumer taste and the symbolic meanings of consumer products.

${ }^{9}$ Wright further differentiated owners' class into those who employ more than 10 people and those who employ fewer than 10 people.

${ }^{10}$ Based on John Keynes' absolute income hypothesis, $C_{t}=a+b I_{t}+U_{t}$; $C_{t}$ refers to a family's consumption at the time period of $t$; $a$ is the intercept; $I_{t}$ refers to a family's income at the time period of $t$; and $b$ refers to MPC.

${ }^{11}$ Individuals who live alone are regarded as single-person households.

${ }^{12}$ It is noted that the population in the labour force differs from the labour force. In demographic studies, people aged between 15 and 60 or between 15 and 64 are seen as the labour force, although some actually do not participate in the labour force. The population in the labour force refers to those who are actually working. The CSS only records data regarding occupation and income of this group.

${ }^{13}$ According to existing data, among Asian nations, the proportion of owners' class or employers' class in the labour force is relatively high; but amongst Western countries, this proportion is relatively low.

${ }^{14}$ When we classify income level into different aliquots, some studies' calculations have shown an inverted $U$ shape, whereas some studies show a saddle shape (see Yang and Zhu 2007).

${ }^{15}$ Many places have called for a change in prevailing habits and customs, such as for weddings and funerals, but failed to achieve their desired results. One important reason is that the traditional form of kinship-based network is still widely accepted. Even in modernized urban communities, if people still live in an 
acquaintance-oriented environment, consumption aims to maintain such kind of network are inevitable.

${ }^{16}$ During the process of enterprise restructuring (from the end of the 1990s to the early twenty-first century), the number of group enterprises fell gradually. Within prefecture-level cities, there are few state-owned enterprises left. Most workers from collectively owned enterprises have been transferred to private enterprises, or retired after being bought out of service. But in the process of reforming state-owned enterprises, the initial call for "cutting down staff and increasing efficiency" was turned into "substituting staff and increasing efficiency", that is to say, by turning staff into migrant workers, one is able to reduce the cost of labour. This is often called "old people old ways, new people new ways".

${ }^{17}$ The pension of enterprise workers in urban areas increased by $6.5 \%$ in 2016 , according to the report distributed by the Ministry of Human Resources and Social Security of the People's Republic of China 2016.

${ }^{18}$ Although the Chinese real estate boom, supported by the persisting high housing price, has brought huge financial revenues for the government, it also employed the market's hand to deprive people's (especially for those whose main purpose is to settle) consumption on other commodities.

${ }^{19}$ Even in major cities like Beijing, Shanghai, Guangzhou, and Shenzhen, the government does not limit the number of properties a private company can buy under its name.

${ }^{20}$ After completing a calculation based on information from the Sixth National Census, average life expectancy in China reached 74.83 years in 2010, which is a 3.43 years higher than 10 years earlier (see Xinhua Press 2012).

${ }^{21}$ Since December 2007, "taking home appliances to the countryside" was an experimental campaign that began in Shandong, Hunan, and Sichuan provinces as well as in Qingdao city. Peasants' purchasing home appliances could receive a financial subsidy of $13 \%$ if they were within the targeted income range. Beginning in February 2009, this policy was implemented nationwide. Later, the Ministry of Finance, the Ministry of Commerce, and the Ministry of Industry and Information Technology announced "Notice on the issues related to the expiration of the taking home appliances to the countryside policy"; the policy ended on January 31, 2013.

${ }^{22}$ Based on "Plan for adjusting and stimulating the car industry" published by the State Council on January 14, 2009, from March 1 to December 31, 2009, those purchasing small cars with a motor vehicle emissions of less than $1.3 \mathrm{l}$ and either discarding entirely or trading in three-wheeled vehicles or low-speed trucks for light-capacity trucks would receive a one-time financial subsidy. In early 2010, the "taking cars to the countryside" plan was postponed to December 31 of the same year.

${ }^{23}$ Given the lack of market supervision in China, it is exactly those health products of unknown origin that have severely damaged the health of the elderly population, increasing their financial burden in health care.

${ }^{24}$ Based on the 2015 CSS data, after converting household property assets per capita into present value, the Gini Coefficient represented by property assets reaches approximately 0.6 . 


\section{Publisher's Note}

Springer Nature remains neutral with regard to jurisdictional claims in published maps and institutional affiliations.

Received: 22 October 2017 Accepted: 4 December 2017

Published online: 22 December 2017

\section{References}

Baudrilliard, Jean. 2001. The Consumer Society: Myths and Structures (in Chinese), translated by Liu Chengfu and Quan Zhigang. NanJing: NanJing University Press.

Bauman, Zygmund. 2013. Globalisation - the Human Consequences (in Chinese), translated by Guo Guoliang. Xu Jianhua: The Commercial Press.

Becker, Gary S.. 1987. A Treatise on the Family (in Chinese), translated by Feng Jiansong. Beijing: Huaxia Press.

Bell, Daniel. 2010. The Cultural Contradictions of Capitalism (in Chinese), translated by Zhao Yifan et al. Beijing: People's Press.

Bourdieu, Pierre. 2015. Distinction: A Social Critique of the Judgement of Taste (in Chinese), translated by Liu Hui. Beijing: The Commercial Press

Dai, Huishi, and Hanlong Lu. 2001. Consumer culture and consumption revolution. Sociological Studies 5: 117-125.

Li, Chunling. 2011. The consumption standards and modes of Chinese middle class. Guangdong Social Sciences 2: 210-218.

Li, Peilin, and Zhang Yi. 2001. Consumption stratification: another perspective for economy start-up. Social Sciences in China 2: 52-61.

Li, Shi, and Chuliang Luo. 2012. The short-term changes and long-term tendency for income disparity in China. Comparative Economic \& Social Systems 4: 186-194.

Li, Xiaoyu. 2016. Chinese Gene Coefficient's Seven Continuous Drop and the Wealth Gap Continues to Shrink. http:// ww.gov.cn/zhengce/2016-01/20/content_5034573.htm. Accessed 22 Nov 2017.

Marx, Karl. 1961. Wage labour and capital. Beijing: People's Press.

Rostow, Walt Whitman. 1962. The stages of economic growth. Beijing: The Commercial Press.

Simmel, Georg. 2001. 时尚的哲学 (in Chinese), translated by Fei Yong et al. Beijing: Culture and Art Publishing House. Veblen, Thorstein. 1964. Theory of the Leisure Class (in Chinese), translated by Chai Shoubai. Beijing: The Commercial Press.

Wang, Jianping. 2007. The consumer behaviour of the Chinese middle class. Beijing: The Chinese Encyclopaedia Press. Wang, Ning. 2009. From ascetic society to consumption society. Beijing: Social Science Academic Press.

Wright, Erik Olin. 2004. Class Counts: Comparative Studies in Class Analysis (in Chinese), translated by Cheng Xinxiang, Shenyang: Liaoning Education Press.

Xiaohong, Zhou. 2005. Chinese middle class survey. Beijing: Social Sciences Academic Press.

Xinhua Press. 2012. http://news.sohu.com/20120810/n350317599.shtml. Accessed 22 Nov 2017

Yang, Tianyu, and Shi'e Zhu. 2007. Studying the inverted U shape relationship between the income of Chinese residents and their marginal consumption tendency. Journal of Renmin University of China 3: 49-56.

Zhang, Yi. 2003. The continuation of intra-class marriage. Chinese Journal of Population Science 4: 39-47.

Zhu, Di. 2012. Methodology, research strategies, and the application of triangulation-a case study of consumption modes. Sociological Studies 4: 146-166.

Submit your manuscript to a SpringerOpen ${ }^{\circ}$ journal and benefit from:

- Convenient online submission

- Rigorous peer review

Open access: articles freely available online

High visibility within the field

Retaining the copyright to your article 